\title{
1 The influence of socioeconomic change and culture on intergenerational relations ${ }^{1}$
}

\author{
Gisela Trommsdorff
}

Erschienen in: Youth in education: The necessity of valuing ethnocultural diversity / Timmerman, Christiane; Clycq, Noel; MacAndrew, Marie et al. (Hrsg.). - London: Routledge, 2016. - S. 11-26. - ISBN 978-1-138-99960-2 https://dx.doi.org/10.4324/9781315658148-2

\section{Introduction}

Why is a culture-contextual lens important for the study of intergenerational relations? Intergenerational relations can be viewed from a structural perspective focusing on the relationships among different cohorts who share the same historical and sociocultural background in their socialization experiences (Mannheim, 1929/1964). Different from this approach is the psychological perspective on biologically and psychologically related individuals from different generations within a family. Intergenerational relations influence one's individual development by transmitting cognitive, motivational, social and emotional resources. Furthermore, intergenerational relations may also influence the sociocultural and economic context, e.g. economic exchange among generations, stability of families, changes of cultural values. At the same time, taking an ecocultural perspective, intergenerational relations are influenced by the sociocultural and economic context. Accordingly, intergenerational relations are related to cultural values in several ways. They function to transmit certain values from one generation to the next, and they are shaped by the respective value orientation in a culture.

Adolescents play a major role in this process since they are developing value preferences as part of their identity development, which in turn is influenced partly by the quality of the parent-child relationship. The parent-child relationship influences the child's social, cognitive, and emotional development, which in turn is relevant in the development of intergenerational relations throughout the lifespan (Albert \& Trommsdorff, 2014; Trommsdorff, 2006). For example, attachment relationships in early childhood are the basis of further developmental outcomes, including the later relationship with one's ageing parents.

Additionally, parents and their children generally share the same cultural context and related developmental conditions that influence parenting, the parent-child relationship, and the relationships with family members from different generations. Thus, we conceive of parent-child relationships as a specific element within a network of extended intergenerational relationships that is in turn embedded in a particular cultural context and its value system. This view is informed by Bronfenbrenner's (1979) ecocultural model of development. 
In line with Schwartz $(1992,2007,2012)$, we understand value orientations as motivating and guiding individual behaviour (Trommsdorff, 2012b). Schwartz claims universality of ten basic human values with distinct goals. The relative importance of these values may change over time, especially in times of socioeconomic and cultural changes. Here, the question arises about what kind of value changes adolescents are experiencing, and how these changes are affecting adolescent development and also intergenerational relations in a society. Part of such value changes are preconditions for and consequences of intergenerational relations, particularly with respect to the current widespread globalization. All over the world, ongoing fundamental demographic changes - increasing life expectancy and decreasing birth rate - are interrelated with major economic and social changes, and respective changes in value orientations and intergenerational relations in the family.

Until after the Second World War, a typical traditional family consisted of three generations - grandparents, parents and children - with all three generations usually living together in one household. However, during the last decades ongoing socioeconomic, demographic and cultural changes have affected this family structure significantly (Bertram \& Ehlert, 2012). Changing economic and social resources, and related value orientations of the older and younger generation have also affected changes in intergenerational relations.

For example, the increasing life expectancy implies a potentially longer life span shared among generational cohorts differing in age. However, decreasing birth rates as part of the demographic change are giving rise to sociopolitical concerns, e.g. regarding justice in the distribution of resources among the generations. It is discussed whether conflicts between the generations may arise due to the economic strain of young cohorts who are supposed to carry the burden of supporting the elderly.

Sociocultural changes imply questions about how parent-child relationships will change, and how and on which basis family members, especially children and ageing parents, can expect to receive and provide care and support. Ongoing sociocultural changes may cause more individualization related to a dissolution of family bonds, or it may activate a revival of fruitful and mutually supportive intergenerational relations. Here, psychological and sociological approaches are needed to clarify the complexity of the ongoing changes, the conditions for and the consequences of changes in intergenerational relations, and the role of adolescents and their value orientations in this process.

Here, I conceptualize intergenerational relations as relationships between individual, biologically connected members of a family who belong to different generations. Accordingly, my interest is in children's relations to their parents and grandparents, and parents' relations to their own parents (children's grandparents). These relations are asymmetrical and bidirectional, and they imply a long-term commitment usually based on trust and reciprocity.

Bengtson (2000) and Bengtson and Roberts (1991) have suggested a model of family solidarity to characterize intergenerational relations in the family. However, 
social change in families due to individualization, geographic mobility, separation, step-parenting and changes during the individual life course may undermine lifelong solidarity relations among family members and thereby affect children's sense of responsibility with respect to supporting their ageing parents (Silverstein \& Conroy, 2009). The question remains: what effect does the dissolution of both sociocultural norms as well as biological and economic bonds have on the parentchild relationship? Is its socioemotional quality perhaps thereby affected?

Moreover, since parent-child relations do not remain the same over time, studies of intergenerational relations need a lifespan approach that takes various age groups into account: beyond extending the notion of parent-child relations to more than only two generations (including grandparents, parents, and children), I argue that the developmental age and the developmental process in parent-child relations should be considered (Trommsdorff, 2006).

This perspective borrows from psychological research that shows how closely individual development is related to the family and the cultural context. The quality of the early parent-child relationship sets the tone for further developmental outcomes of the child, including internalization of values, social and emotional competence, resilience to risks, coping with challenges, and prosocial motivation for supporting ageing parents. Therefore, early parent-child relations (based on attachment, see Bowlby, 1969, 1988) can partly predict the quality of intergenerational relations in the family through the generations. Furthermore, the quality of relations among generations is assumed to be an important factor in the structure of societies, and the socialization function of the family, affecting the continuity of cultural values.

Most research on intergenerational relations have studied Western, EuropeanAmerican samples, largely ignoring the diversity of cultures and the impact of the cultural context on societal and interpersonal phenomena (named 'WEIRD: Western, Educated, Industrialized, Rich, and Democratic' by Henrich et al., 2010). This is especially problematic given the ongoing trends in demographic changes, migration and urbanization, and continuous political and socioeconomic changes in most parts of the world. In order to avoid an ethnocentric bias, more crosscultural studies that focus specifically on culture are needed (Trommsdorff \& Nauck, 2005, 2006, 2010). These could test the universality and culture-specificity of intergenerational relations and their socioeconomic and culture-psychological correlates. Cultures are not homogeneous entities; they are continuously changing in various aspects and directions, which makes it difficult to form a cultureinformed theory on intergenerational relations. However, one may start from some general psychological assumptions and their empirical validation and focus on to what extent psychological implications of the context influence the theoretically interesting relations among the variables under study. Using this framework, the present study deals with intergenerational relations in diverse cultural contexts, partly based on theoretical perspectives and results from the international Valueof-Children and Intergenerational Relations Study (VOC-IR) (Trommsdorff \& Nauck, 2010). 
My focus is first and foremost on demographic and value change in diverse cultures. Second, I discuss issues of intergenerational transmission of values. Third, I deal with questions of support in the family between the generations.

\section{Demographic change and changing values of the family}

Globalization and demographic shifts are affecting societies and families all over the world, especially in terms of value changes (Bertram \& Ehlert, 2012). Life expectancy in most industrialized countries is continuously rising, while fertility rates are continuously declining. This ongoing pattern implies an increase in the relative number of old people and a relative decrease of the younger generation. Additionally, the divorce rate and different patterns of family structure (e.g. living apart together) have been increasing (Nave-Herz, 2012). As a consequence, people are facing the prospect of living in their old age without close family ties. In all European countries, persons above age 80 are reported to be living alone (BörschSupan et al., 2005). Whether this implies loneliness and dependency on professional care is an empirical question. Recent studies show considerable differences in loneliness between South-European and North-European countries (Börsch-Supan et al., 2005).

Regarding non-European countries, significant changes also abound. Japan has undergone enormous transformations in a short time, from being an agrarian to an industrial and a post-industrial society. At present, it is experiencing a shrinking population due to low birthrate, and at the same time the highest percentage of elderly in the world. These changes have significant effects-on the family and on intergenerational relations, partly also since traditional values of 'filial piety' are declining (Linhart, 2012).

Fertility rates in less economically developed countries such as those in SubSaharan Africa remain rather high, while the life expectancy of the population increases due to improved medical care. An increasing number of young people who are facing unemployment and poverty choose to migrate, leaving their ageing parents. Thus, socioeconomic and demographic change affect family as well as care of the older generation (e.g. Ntozi, 2012).

Socioeconomic changes are related to demographic changes, especially insofar as both imply value changes. Values have been conceived of as motivating individuals to achieve certain goals. Values may differ between individual societies, and also depend on the cultural context and related cultural values (e.g. rather individualistic goals of independence, autonomy, and self-reliance are in contrast to rather collectivistic goals of interdependence and relatedness). On the cultural level, values function as a basis for social rules and legitimation of institutions integrating individuals into the society (see Trommsdorff, 2012a) and characterizing culture-specific general tendencies. Considerable value change from materialistic (e.g. security) to post-materialistic values (e.g. self-fulfilment) has been observed in European industrialized societies (Inglehart, 1997). This change has been accompanied by changes in family values (e. g. decreasing preference of extended to increasing preference of nuclear families and single households), and changes in the 
value of children in society (Kagitcibasi, 2007; Trommsdorff, 2012b; Trommsdorff \& Nauck, 2005).

Trommsdorff and Nauck $(2005,2006)$ relate demographic changes to changes in parent-child relationships and in the value of children in different cultural contexts. In traditional societies with less economic development, children are valued in terms of how much social status and old-age security they provide. Here, one can say that the economic and social value of children is higher than in more industrialized societies, where children are primarily valued for how much emotional reward they provide the parents. This may explain the decreasing fertility rate in industrialized countries, since more than one or two children would not necessarily provide a higher degree of emotional satisfaction (Mayer et al., 2005). In contrast, in less industrialized countries, each child is potentially contributing to the parents' old age security, thereby reinforcing the economic or material value of children (Kim \& Park, 2005; Mishra et al., 2005; Trommsdorff \& Mayer, 2012). In his cross-cultural study on adolescents' family models, Mayer $(2009,2013)$ has shown how the interdependent family model is related to the material value of children, while the independent family model is related to the emotional value of children (Mayer \& Trommsdorff, 2010, 2012). Furthermore, in a cross-cultural and multilevel study we have shown how adolescents' value of children is related to the intention to have children in the future. Most adolescents from diverse cultures wish to have children and are motivated by expecting close and satisfying emotional relationships with their offspring - thus clearly giving priority to an emotional (in contrast to an economic or social) value of children (Mayer \& Trommsdorff, 2010).

\section{Transmission of values}

Intergenerational relations in the family are an important basis of socialization processes. Here, the transmission of values and behavioural preferences between the generations are grounded. Values can be transmitted from the older to the younger generation and vice versa, thereby influencing the direction of value change or cultural continuity (Trommsdorff, 2009a). The transmission of values follows both vertical (e.g. parent-child relations) and horizontal (e.g. peer relations; dyadic partnership; 'Zeitgeist') directions. Transmission is based on interaction processes among components of the microsystem - that is, in the family, school, peers and neighbourhood. According to Bronfenbrenner's (1979) ecosystem approach, the microsystem is embedded in and interacting with the meso- and exosystem (mass media, friends of family, legal and social welfare services), while these are interacting with the macrosystem (cultural values, religion, ideologies). An ecosystem approach assumes bidirectionality in the transmission of values.

Under which conditions are values transmitted within the family, between parents and grandparents, and children (grandchildren)? According to cultureinformed studies on the transmission of values, the quality of intergenerational relations is a relevant predictor for successful internalization of the respective parental values (Albert \& Trommsdorff, 2014; Trommsdorff, 2009a). Parenting and parentchild relations are the transmission belt for the culture-specific transmission of 
parental values. However, parenting alone cannot explain whether the intended transmission of values is successful or not. In order to understand the transmission process and successful internalization of the parents' values, it is necessary to study the features of parental disciplinary behaviour, whether the parents' intentions are accurately perceived by the child, and also whether the child accepts the parents' message (Grusec \& Goodnow, 1994). The child's acceptance of parents' goals and values in turn depends on the parent-child relationship, especially the quality of attachment (Trommsdorff, 2009a). This model for the process of internalization is useful to describe the successful transmission of values from the parents to their children.

In empirical studies, several difficulties have to be solved. Whether the child accurately perceives parental values, and whether the child accepts the parental message, probably depends on the quality of the parent-child relationship and the cultural context. For example, in our studies on adolescents' perception of parental control, German adolescents overall felt rejected with respect to their parents' control and monitoring, while Japanese adolescents felt accepted and satisfied (Trommsdorff, 1985, 2015).

Furthermore, the empirical assessment of parenting is difficult due to its complex multifaceted characteristics of e.g. warmth and control or acceptance and rejection (Maccoby, 2000; Rohner \& Cournover, 1994; Rohner \& Pettengill, 1985). Baumrind's (1968) distinction among authoritarian, authoritative and permissive parenting has been the dominant approach of studies based on Western samples. However, cross-cultural and culture-informed studies have shown that authoritarian parenting has a very different meaning in Asian cultures (Chao \& Tseng, 2002). Moreover, recent research underlines that global measures of parenting neglecting the situational context are insufficient. Therefore, Grusec and Davidov (2010) have suggested a domain-specific approach to parenting.

Of special importance for further development is the early mother-child relationship; this can evoke secure or insecure attachment, the basis for an internal working model of the self and the world (Bowlby, 1969, 1988). Attachment research has shown that sensitive mothers can build an attachment relationship with their child which fosters a secure working model (Grossmann \& Grossmann, 1990). However, again, sensitivity with respect to mothering takes on different meanings in different geographical contexts due to situational and cultural differences (Rothbaum et al., 2006; Trommsdorff \& Friedlmeier, 2010; Ziehm et al., 2013).

Therefore, cross-cultural and domain-specific approaches should be combined for a better understanding of parenting as a transmission belt for values, and the quality of parent-child relations should be specified to predict the transmission and the internalization of values (Albert et al., 2011; Trommsdorff, 2009b). Furthermore, due to the effects of cultural norms and developmental changes, it is not easy to empirically assess whether value transmission was successful or not. For example, correlations between verbal measures of parents' and their children's values should be related to behavioural measures and perceived cultural norms.

Finally, bidirectional influences should be taken into account: children come of age in a particular peer group and adopt values that in turn organize their 
individual and social development, including their interaction with their parents - thereby influencing their parents' value orientations and resulting intergenerational relations. Bidirectional influences can differ among different cultures (Trommsdorff \& Kornadt, 2003).

\section{Intergenerational relations}

Intergenerational relations differ among individuals and also among cultures. Rothbaum et al. (2000) have discussed the cultural differences in intergenerational relations over the lifespan, distinguishing the path of generative tension and the related lens of individuation, and the path of symbiotic harmony with preference for the lens of accommodation. For example, in cultures where individualism and independence is highly valued, the parent-child relationship develops from separation and reunion experiences with the caregiver in early childhood. In childhood, personal preferences are built up; in adolescence and adulthood, negotiations serve as the basis of trust in the relationship. In contrast, in cultures where interdependence and relatedness are highly valued, infancy is characterized by union (mother-child 'oneness'). In childhood, the development of intergenerational relations is based upon understanding and accepting the expectations of others, which in turn furthers the processes of internalization. In adolescence, when stability of the intergenerational relationships is achieved, the assurance of secure relatedness in adulthood is promoted (Rothbaum et al., 2000). The cultureinformed perspective thus allows the analysis of intergenerational relationships over the lifespan by taking cultural values and their transmission in the socialization process into account.

Since intergenerational relations in the family have only rarely been studied cross-culturally, we have started the "Value of Children and Intergenerational Relations' Study (VOC-IR) (Trommsdorff \& Nauck, 2005, 2006, 2010) including three-generation samples from 20 countries (in each country about 1,000 adolescents, 1,000 mothers and 100 grandparents) (in some countries intracultural comparisons of urban and rural samples were carried out). This project has been designed to study the quality of intergenerational relations in the cultural context for predicting value transmission and support for ageing parents (Schwarz \& Trommsdorff, 2005a). We started from a lifespan perspective in order to be able to study later stages in the parent-child relation as well as relations between nonadjacent generations, such as grandchildren and grandparents. Therefore, our theoretical framework is based on an ecocultural and developmental approach. Our culture-informed model of intergenerational relationships across the lifespan considers parent-child relationships as embedded in the socioeconomic and cultural context (Trommsdorff, 2006).

The model to be tested includes (1) contextual factors, e.g. cultural values and socioeconomic factors, (2) person variables such as attachment and individual value orientations, (3) relationship variables regarding the child (e.g. preferred child-rearing practices and investments in the child) and regarding the parents as well (e.g. given support to pursue these goals) (Trommsdorff, 2001; Albert \& Trommsdorff, 2014) 


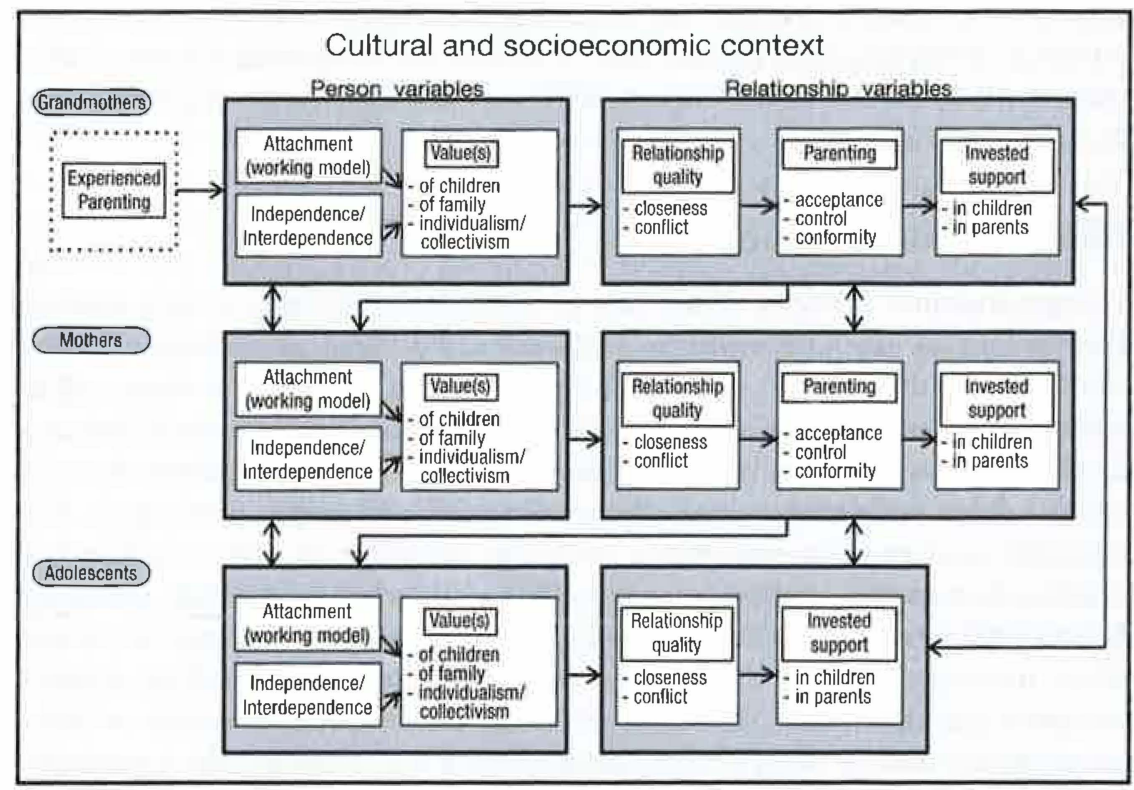

Figure 1.1 Parent-child relations in three generations (the VOC-IR Study)

(see Figure 1.1). The relationships among these three aspects (context, person, parent-child relationship) were studied for three (biologically related) generations: adolescents, mothers, and grandmothers. Originally, six cultures were included in the study (Germany, Israel, Turkey, Republic of Korea, China and Indonesia). In the meantime, researchers from different parts of the world have joined the project, and currently, a large dataset ( $N=16.461$ participants) is available from nineteen different countries on four continents (Trommsdorff \& Nauck, 2005, 2006, 2010). Multilevel analyses take context, person and relationships into account (e.g. Mayer \& Trommsdorff, 2010).

The main question was whether socioeconomic changes affect value change (individualism/collectivism; family values; the value of children) and the quality of intergenerational relations. The basic hypothesis is as follows: there is mutual interaction between parents' and their children's values in all three generations, and that interaction is in turn influenced by the extent to which it is embedded in its sociocultural context. Accordingly, the analyses focused on person variables and relationship variables and their respective interrelations (see Figure 1.1). Some selected results from the VOC-IR Study are summarized in the following.

\section{Value of children and the family}

The emotional value of children was high in all countries, however, significant differences occurred with respect to the utilitarian (socioeconomic) value of 
children: the more economically developed countries (e.g. Germany, France) are less in favour of utilitarian values of children as compared to less economically developed countries (e.g. China, India, Russia). Furthermore, in all countries, the older generation (grandparents) favour utilitarian values of children more than their adult daughters do (Trommsdorff \& Mayer, 2012). Whether this difference in values depends on a value change or on the developmental age remains an open question.

Value orientations (measured on the individual level) are related to certain macro-level factors (measured on the cultural level). The Human Development Index (HDI) is positively associated with the emotional value of children and negatively associated with family values for both grandmothers and adult daughters. Additionally, individualism (measured as cultural dimension according to Hofstede, 1980 ) is negatively related to collectivism and family values, again, for both generations (Trommsdorff \& Mayer, 2012).

Post-materialistic values (measured according to the World Value Survey 1990-1992) correlate negatively with the socioeconomic (utalitarian) value of children in Germany and France and positively in South Africa and India, while Japan, Korea and China are about in-between these two groups (cluster analyses) (Trommsdorff, 2006).

\section{Giving and receiving support between the generations}

According to Bengtson (2000), solidarity should characterize the families even in times of individualization. However, the question is whether respective positive results for European-American families also hold for other countries (Bengtson et al., 2000). The VOC-IR study allows the comparison of mean values of giving and receiving support across diverse cultures. The results show that in East Asian and Western countries, support given to the elderly mother (grandmother) by her adult daughter is lower than the support given by the grandmother to the adult daughter. However, in Germany, the given and received support is much lower than in China and Indonesia, while Korea is situated in the middle (Schwarz \& Trommsdorff, 2005b). A closer look at the kind of support given by the adult daughters to their elderly mothers (grandmothers) shows that German adult daughters give less emotional, even less instrumental, and much less financial support as compared to Chinese and Korean adult daughters. German adult daughters distinguish clearly among the different kinds of support. When they do provide support, they prefer to give emotional support.

Adolescents in traditional, collectivistic cultures (Indonesia, India, Turkey, South Africa) who experience a conflict between helping their parents or meeting friends tend to prefer to help their parents. However, in individualistic cultures, adolescents facing the same/similar conflict prefer to meet up with their friends (Mayer \& Trommsdorff, 2012; Schwarz et al., 2012).

It is known from studies in lifespan intergenerational relations in Western countries that the anticipation of giving support to one's elderly parents can be a burden for children, adolescents and adults. In Asian cultures, children are normatively expected to support their elderly parents. Based on the Confucian tradition 
of filial piety, this filial duty is strongly established. However, in Western countries, the intention to support one's elderly parents is based on the individual decision and related prosocial motivation. Research in prosocial motivation has shown that a positive relationship with the person in need facilitates the motivation to help and give support (e.g. Eisenberg et al., 2006; Staub, 1980). Therefore, more individual differences in support should be expected in those countries where values of individualism are high as compared to more traditional and collectivistic countries. More psychological conflict should also be expected in individualistic cultures since support is based on individual decision-making and related prosocial motivation. Empirical results from the VOC-IR study clearly show significant differences in the correlation between individualism (Hofstede's cultural dimension) and filial anxiety among the diverse countries with low individualism associated with low filial anxiety. This is the case for China, Turkey and India, while in Germany and France individualism is higher and at the same time filial anxiety is more pronounced.

Do these results indicate less intraindividual and intergenerational conflicts in traditional compared to more modern societies? Here, cultural differences in the conditions and functions of emotions (such as anxiety) have to be taken into account as part of culture-specific effects of socioemotional development (Trommsdorff \& Cole, 2011). Therefore, it should be noted that our results show more filial anxiety when intergenerational relations are based on personal decisions, as is the case in individualistic cultures. In contrast, in traditional and collective cultures where cultural values of filial piety prevail, the normative expectation to support one's elderly parents is very strong; moreover, the general value to stabilize harmony in one's in-group and the emotional bond that underlies that value contribute to the very low probability of intra-individual conflicts. Our data clearly demonstrate that intergenerational conflicts are less pronounced in traditional, norm-oriented societies such as India, in contrast to Germany and France (Trommsdorff \& Mayer, 2012).

\section{Summary and outlook}

\section{Summary}

So far, the empirical studies across different cultures have shown that intergenerational relations in the family as well as cultural values are important in the individual's development over his/her lifespan. They serve as a transmission belt for the transmission and internalization of values, but also serve the function of giving and receiving support between the generations. Our results have also shown that the quality of the relationship is important for both the transmission of values, and for the mutual support between the generations.

The results from our VOC-IR study are clearly in line with the assumptions based on the model of pathways for intergenerational relations over the lifespan by Rothbaum et al. (2000). The intergenerational relationship in individualistic cultures is more characterized by generative tension, while in collectivistic and interdependent cultures, it is more characterized by symbiotic harmony. The results 
from our VOC-IR study are only partly in line with the assumptions by Kagitcibasi (2007), since we could not observe the predicted direct change of cultures (high in independence and of cultures high in interdependence) towards a symbiosis of emotional interdependence. Our results are based on multilevel analyses involving very different cultures. However, in future research, the processes and effects of ongoing multi-facet cultural changes should be assessed.

The results of our studies do in general fit to Bengtson and Roberts's (1991) model of intergenerational solidarity, which had not previously been tested in largescale cross-cultural comparisons. This underlines the assumption that socioeconomic changes do not disrupt family solidarity and mutual support among the generations in the family.

\section{Outlook}

In the present chapter, I could not report about gender effects in intergenerational relations. However, this is a very interesting issue, deserving more attention in culture-informed studies. Much of ongoing gender-related value change and change in intergenerational relations can be directly linked to cultural values. For example, in many traditional societies (e.g. in East and South East Asia), the eldest son is obliged to be in charge of honouring the ancestors, thus contributing to the continuity of the family. Or in India, the daughter has to leave her family of origin after marriage and live in her husband's household, fulfilling duties of a daughter to the mother-in-law. Cultural change of the patriarchal family system in Japan has resulted in substantial change with respect to the value of children and the value of family, including the role of men and women: three-generation households are decreasing, an increasing number of men and women do not marry (or get divorced at a later age), while the value of having a daughter instead of having a son (who has to fulfil duties in the service of the family and the ancestors) has been increasing (e.g. Linhart, 2012).

The transmission of values depends among other variables on the 'Zeitgeist' and the homogeneity of the context. Hence, the intergenerational relations in migrant families is an important area for future research, especially regarding questions of support and transmission of values (see Albert \& Trommsdorff, 2014; Barni et al., 2012). For example, studies on migrants and non-migrants in Germany, in the Netherlands (Phalet \& Schönpflug, 2001; Schönpflug, 2001), and in Israel (Knafo et al., 2009) found more similarities than differences between cultural groups. These studies clarified the importance of the culture-specific meaning of parenting variables for value transmission.

Since the transmission of values has implications for intergenerational relations and well-being, culture-informed studies on migrant families are of special importance. Hadjar et al. (2012) who have compared adolescents from migrant and minority families to majority families in Germany and Israel were able to show that value similarity between adolescents and their parents might promote wellbeing in families from the majority culture. Adolescents' well-being from migrant 
(or minority) families depends on the similarity of their families' values with the general cultural value orientation ('goodness-of-fit'). A related question has been asked by Albert, Ferring and Michels (2013) in their study on the function of intergenerational value similarity for intergenerational solidarity in migrant and non-migrant families in Luxembourg. Their results show that shared values within the family promote supportive intergenerational relations. However, sharing values does not mean 'absolute' value similarity (independent of situations), which is less preferable for intergenerational solidarity, while 'relative' value similarity (taking into account given circumstances) allows for flexibility between generations.

These studies aim to contribute to a better understanding of universal and culture-specific processes of development over the lifespan, the transmission of values over several generations in the family and the basis of support between the generations. The conditions and consequences of intergenerational relations and sociocultural change may thereby be clarified.

\section{Note}

1 This chapter is based on the international 'Value of Children and Intergenerational Relations Study (VOC-IR)', PI: Gisela Trommsdorff and Bernhard Nauck, supported by the German Research Council (Tr 169/1-4).

\section{References}

Albert, I. \& Trommsdorff, G. (2014). The role of culture in development over the life span: An interpersonal relations approach. Online Readings in Psychology and Culture, 6. doi: http://dx.doi.org/10.9707/2307-0919.1057.

Albert, I., Ferring, D. \& Michels, T. (2013). Intergenerational family relations in Luxembourg: Family values and intergenerational solidarity in Portuguese immigrant and Luxembourgish families. European Psychologist, 18(1), 59-69. doi: 10.1027/1016-9040/ a000125.

Albert, I., Trommsdorff, G. \& Sabatier, C. (2011). Patterns of relationship regulation: German and French adolescents' perceptions with regard to their mothers. Family Science, 2, 58-67.

Barni, D., Knafo, A., Ben-Arieh, A. \& Haj-Yahia, M. M. (2012, March). Parent-child value similarity within and across cultures. In W. Friedlmeier (Chair), Intergenerational Relations and Transmission of Values in Cross-cultural Comparison. Symposium conducted at the Value of Children and Intergenerational Relations Workshop, University of Konstanz, Germany.

Baumrind, D. (1968). Authoritarian vs. authoritative parental control. Adolescence, 3, 255-72.

Bengtson, V. L. (2000). Beyond the nuclear family: The increasing importance of multigenerational bonds (The Burgess Award Lecture). Journal of Marriage \& the Family, 63, $1-16$.

Bengtson, V. L. \& Roberts, R. E. L. (1991). Intergenerational solidarity in aging families: An example of formal theory construction. Journal of Marriage and the Family, 53, 856-70.

Bengtson, V. L., Kyong-Dong, K., Myers, G. C. \& Eun, K.-S. (eds). (2000). Aging in East and West: Families, States, and Elderly. New York: Springer Publishing Company.

Bertram, H. \& Ehlert, N. (eds). (2012). Family, Ties and Care: Family Transformation in a Plural Modernity. Opladen, Germany: Barbara Budrich. 
Börsch-Supan, A., Brugiavini, A., Jürges, H., Mackenbach, J., Siegrist, J. \& Weber, G. (2005). Health, Aging and Retirement in Europe: First Results from the Survey of Health, Aging and Retirement in Europe. Mannheim: Mannheim Research Institute for the Economics of Aging (MEA).

Bowlby, J. (1969). Attachment and Loss: Vol. 1. Attachment. London: Hogarth Press.

Bowlby, J. (1988). A Secure Base: Parent-Child Attachment and Healthy Human Development. New York: Basic Books.

Bronfenbrenner, U. (1979). The Ecology of Human Development: Experiments by Nature and Design. Cambridge, MA: Harvard University Press.

Chao, R. \& Tseng, V. (2002). Parenting of Asians. In M. H. Bornstein (ed.), Handbook of Parenting: Vol. 4. Social Conditions and Applied Parenting (2nd edn, pp. 59-93). Mahwah, NJ: Lawrence Erlbaum Association.

Eisenberg, N., Fabes, R. A. \& Spinrad, T. L. (2006). Prosocial development. In W. Damon, R. M. Lerner \& N. Eisenberg (eds), Handbook of Child Psychology: Social, Emotional, and Personality Development (pp. 646-718). New York: Wiley.

Grossmann, K. E. \& Grossmann, K. (1990). The wider concept of attachment in crosscultural research. Human Development, 33, 31-47.

Grusec, J. E. \& Davidov, M. (2010). Integrating different perspectives on socialization theory and research: A domain-specific approach. Child Development, 81, 687-709.

Grusec, J. E. \& Goodnow, J. J. (1994). Impact of parental discipline methods on the child's internalization of values: A reconceptualization of current points of view. Developmental Psychology, 30, 4-19.

Hadjar, A., Boehnke, K., Knafo, A., Daniel, E., Musiol, A.-L., Schiefer, D. \& Möllering, A. (2012). Parent-child value similarity and subjective well-being in the context of migration: An exploration. Family Science, 3, 55-63.

Henrich, J., Heine, S. J. \& Norenzayan, A. (2010). The weirdest people in the world? Behavioral and Brain Science, 33, 61-83.

Hofstede, G. H. (1980). Culture's Consequences: International Differences in Work-related Values. Los Angeles, CA: Sage Publications.

Inglehart, R. (1997). Modernization and Postmodernization: Cultural, Economic, and Political Change in 43 Societies. Princeton, NJ: Princeton University Press.

Kagitcibasi, C. (2007). Family, Self, and Human Development Across Cultures: Theory and Application (2nd edn). Mahwah, NJ: Erlbaum.

Kim, U. \& Park, Y.-S. (2005). Family, parent-child relationships, fertility rates, and values of children in Korea: Indigenous, psychological, and cultural analysis. In G. Trommsdorff \& B. Nauck (eds), The Value of Children in Cross-cultural Perspective: Case Studies from Eight Societies. Lengerich, Germany: Pabst Science.

Knafo, A., Assor, A., Schwartz, S. H. \& David, L. (2009). Culture, migration, and family value socialization: A theoretical model and empirical investigation with Russian-speaking youth in Israel. In U. Schönpflug (ed.), Cultural Transmission: Developmental, Psychological, Social, and Methodological Perspectives (pp. 269-96). New York: Cambridge University Press.

Linhart, S. (2012). Intergenerational relations in Japan's aged society. In H. Bertram \& N. Ehlert (eds), Family, Ties and Care: Family Transformation in a Plural Modernity (pp. 379-92). Opladen, Germany: Barbara Budrich.

Maccoby, E. E. (2000). Parenting and its effects on children: On reading and misreading behavior genetics. Annual Review of Psychology, 51(1), 1-27. doi: doi:10.1146/annurev. psych.51.1.1.

Mannheim, K. (1929/1964). Das Problem der Generationen (The Problem of Generations). Köln, Germany: Westdeutscher Verlag. 
Mayer, B. (2009). Adolescents' family models: A cross-cultural study (doctoral dissertation, University of Konstanz). Konstanz, Germany: Universitätsbibliothek, KOPS.

Mayer, B. (2013). Family change theory: A preliminary evaluation on the basis of recent cross-cultural studies. In I. Albert \& D. Ferring (eds), Ittergenerational Relations: European Perspectives on Family and Society (pp. 167-87). Cambridge: Policy Press.

Mayer, B. \& Trommsdorff, G. (2010). Adolescents' value of children and their intentions to have children: A cross-cultural and multilevel analysis. Journal of Cross-Cultural Psychology, 41, 671-89. doi: 10.1177/0022022110372195.

Mayer, B. \& Trommsdorff, G. (2012). Cross-cultural perspectives on adolescents' religiosity and family orientation. In G. Trommsdorff \& X. Chen (eds), Values, Religion, and Culture in Adolescent Development (pp. 341-69). New York: Cambridge University Press.

Mayer, B., Albert, I., Trommisdorff, G. \& Schwarz, B. (2005). Value of children in Germany: Dimensions, comparison of generations, and relevance for parenting. In G. Trommsdorft \& B. Nauck (eds), The Value of Children in Cross-cultural Perspective: Case Studies from Eight Societies (pp. 43-65). Lengerich, Germany: Pabst Science.

Mishra, R. C., Mayer, B., Trommsdorff, G., Albert, I. \& Schwarz, B. (2005). The value of children in urban and rural India: Cultural background and empirical results. In G. Trommsdorff \& B. Nauck (eds), The Value of Children in Cross-cultural Perspective: Case Studies from Eight Societies (pp. 143-70). Lengerich, Germany: Pabst Science.

Nave-Herz, R. (2012). Familie heute: Wandel der Fanilienstrukturen und Folgen für die Erziehung (Family today: Change of family structure and consequences for parenting) (Vol. 5). Darmstadt, Germany: WBG.

Ntozi, J. (2012). The demographic situation of Sub-Saharan Africa. In H. Bertram \& N. Ehlert (eds), Family, Ties and Care: Family Transformation in a Plural Modernity (pp. 465-80). Opladen, Berlin: Barbara Budrich Publ.

Phalet, K. \& Schönpflug, U. (2001). Intergenerational transmission of collectivism and achievement values in two acculturation contexts: The case of Turkish families in Germany and Turkish and Moroccan families in the Netherlands. Journal of Cross-Cultural Psychology, 32, 186-201.

Rohner, R. P. \& Cournoyer, D. E. (1994). Universals in youths' perceptions of parental acceptance and rejection: Evidence from factor analyses within eight sociocultural groups worldwide. Cross-Cultural Research, 28, 371-83.

Rohner, R. P. \& Pettengill, S. M. (1985). Perceived parental acceptance-rejection and parental control among Korean adolescents. Child Development, 56, 524-8.

Rothbaum, F., Nagaoka, R. \& Ponte, I. C. (2006). Caregiver sensitivity in cultural context: Japanese and U. S. teachers' beliefs about anticipating and responding to children's needs. Journal of Research in Childhood Education, 21, 23-39.

Rothbaum, F., Pott, M., Azuma, H., Miyake, K. \& Weisz, J. (2000). The development of close relationships in Japan and the United States: Paths of symbiotic harmony and generative tension. Clild Development, 71, 1121-42. doi: 10.1111/1467-8624.00214.

Schönpflug, U. (2001). Intergenerational transmission of values: The role of transmission belts. Journal of Cross-Cultural Psychology, 32(2), 174-85. doi: 10.1177/0022022101032 002005 .

Schwartz, S. H. (1992). Universals in the content and structure of values: Theoretical advances and empirical tests in 20 countries. In M. P. Zanna (ed.), Advances in Experimental Social Psychology, Vol. 25 (pp. 1-65). San Diego, CA: Acadenic Press. doi:10.1016/S0065-2601 (08)60281-6

Schwartz, S. H. (2007). Value orientations: Measurement, antecedents and consequences across nations. In R. Jowell, C. Roberts, R. Fitzgerald \& G. Eva (eds), Mensuring Attitudes 
Cross-nationally: Lessons from the European Social Survey (pp. 169-203). London: Sage. doi: 10.4135/9781849209458.n9.

Schwartz, S. H. (2012). Values and religion in adolescent development: Cross-national and comparative evidence. In G. Trommsdorff \& X. Chen (eds), Values, Religion, and Culture in Adolescent Development (pp. 97-122). New York: Cambridge University Press.

Schwarz, B., Mayer, B., Trommsdorff, G., Ben-Arieh, A., Friedlmeier, M., Lubiewska, K., Mishra, R. C. \& Peltzer, K. (2012). Does the importance of parent and peer relationships for adolescents' life satisfaction vary across cultures? Journal of Early Adolescence, 32, 55-80.

Schwarz, B. \& Trommsdorff, G. (2005a). The relation between attachment and intergenerational support. European Journal of Ageing, 2, 192-9.

Schwarz, B. \& Trommsdorff, G. (2005b). Intergenerationaler Austausch von Unterstïtzung und Reziprozität in Kulturvergleich. In A. Steinbach (ed.), Generatives Verhalten und Generationenbeziehungen (pp. 199-212). Wiesbaden: VS Verlag für Sozialwissenschaften.

Silverstein, M. \& Conroy, S. J. (2009). Intergenerational transmission of moral capital across the family life course. In U. Schönpflug (ed.), Cultural Transmission: Psychological, Developmental, Social, Methodological Aspects (pp. 317-37). New York: Cambridge University Press.

Staub, E. (1980). Social and prosocial behavior: Personal and situational influences and their interactions. In E. Staub (ed.), Personality: Basic Aspects and Current Research (pp. 237-94). Englewood Cliffs, NJ: Prentice-Hall.

Trommsdorff, G. (1985). Some comparative aspects of socialization in Japan and Germany. In I. Reyes Lagunes \& Y. H. Poortinga (eds), From a Different Perspective: Studies of Behavior Across Cultures (pp. 231-40). Amsterdam: Swets \& Zeitlinger.

Trommsdorff, G. (2001). Value of Children and Intergenerational Relations: A Cross-Cultural Psychological Study. University of Konstanz, Department of Psychology, Developmental and Cross-Cultural Psychology.

Trommsdorff, G. (2006). Parent-child relations over the life-span: A cross-cultural perspective. In K. H. Rubin \& O. B. Chung (eds), Parenting Beliefs, Behaviors, and ParentChild relations: A Cross-Cultural Perspective (pp. 143-83). New York: Psychology Press.

Trommsdorff, G. (2009a). Intergenerational relations and cultural transmission. In U. Schönpflug (ed.), Cultural Transmission: Psychological, Developmental, Social, and Methodological Aspects (pp. 126-60). New York: Cambridge University Press.

Trommsdorff, G. (2009b). A social change and a human development perspective on the value of children. In S. Bekman \& A. Aksu-Koc (eds), Perspectives on Human Development, Family and Culture: Essays in Honor of Cigdem Kagitcibasi (pp. 86-107). Cambridge: Cambridge University Press.

Trommsdorff, G. (2012a). Development of "agentic" regulation in cultural context: The role of self and world views. Child Development Perspectives, 6(1), 19-26. doi:10.1111/ j.1750-8606.2011.00224.x.

Trommsdorff, G. (2012b). Cultural perspectives on values and religion in adolescent development: A conceptual overview and synthesis. In G. Trommsdorff \& X. Chen (eds), Values, Religion, and Culture in Adolescent Development (pp. 3-45). New York: Cambridge University Press.

Trommsdorff, G. (2015). Cultural roots of values, and moral and religious purposes in adolescent development. In L. A. Jensen (ed.), The Oxford Handbook of Human Culture and Development. New York: Cambridge University Press.

Trommsdorff, G. \& Cole, P. M. (2011). Emotion, self-regulation, and social behavior in cultural contexts. In X. Chen \& K. H. Rubin (eds), Socioemotional Development in Cultural Context (pp. 131-63). New York: The Guilford Press. 
'Trommsdorff, G. \& Friedlmeier, W. (2010). Preschool girls' distress and mothers' sensitivity in Japan and Germany. European Journal of Developmental Psychology, 7, 350-70. doi: 10.1080/17405620802252742.

Trommsdorff, G. \& Komadt, H.-J. (2003). Parent-child relations in cross-cultural perspective. In L. Kuczynski (ed.), Handbook of Dynamics in Parent-child Relations (pp. 271-306). London: Sage.

Trommsdorff, G. \& Mayer, B. (2012). A cross-cultural study of intergenerational relations: The role of socioeconomic factors, values, and relationship quality in intergenerational support. In H. Bertram \& N. Ehlert (eds), Family, Ties, and Care: Family Transformation in a Plural Modernity (pp. 315-42). Berlin, Germany: Barbara Budrich Publishers.

Trommsdorff, G. \& Nauck, B. (eds) (2005). The Value of Children in Cross-Cultural Perspective: Case Studies from Eight Societies. Lengerich, Germany: Pabst Science.

Trommsdorff, G. \& Nauck, B. (2006). Demographic changes and parent-child relationships. Parenting: Science and Practice, 6, 343-60.

Trommsdorff, G. \& Nauck, B. (2010). Introduction to special section for Journal of CrossCultural Psychology: Value of children: A concept for the better understanding of cross-cultural variations of fertility behavior and intergenerational relationships. Journal of Cross-Cultural Psychology, 41, 637-51.

Ziehm, J., Trommsdorff, G., Heikamp, T. \& Park, S. Y. (2013). German and Korean mothers' sensitivity and related parenting beliefs. Frontiers in Psychology, 4, 561. doi: 10. 3389/fpsyg.2013.00561. 